\title{
Discussion on Education Teaching Reform of Clothing Plate and Technology Specialty
}

\author{
Kai Li ${ }^{1}$, Fei Liu $^{2}$ \\ 1,2 Jiangxi Institute of Fashion Technology, Clothing Design Branch, Jiangxi, Nanchang, 330201
}

KEYWORDS: Clothing Plate, Technology Specialty, Education Teaching

\begin{abstract}
At this stage, the major colleges are offering clothing and clothing plate technology courses, however, there is a big different in terms of teaching content and teaching methods, teaching effectiveness and quality of the presence of large differences, strengthen the garment plate and Technology Education and Teaching the study is particularly important.
\end{abstract}

\section{Introduction}

With the progress and development of our social and economic reform and opening up process will continue to move forward, to strengthen communication and exchanges with international. In the garment industry chain, clothing professional education occupy an important position. In the long process of development, China's garment industry to get some progress, transporting a large number of talents to the apparel industry, promote the progress and development of the apparel market and the industry. However, with the change in the apparel industry production management system, the traditional teaching model exposes many problems to be solved, actively innovative clothing plate and Technology Education, cultivating excellent talents.

\section{The Status of Clothing Plate and Technology Education Teaching}

As a practical, strong discipline, professional clothing attaches great importance to the combination of theory and practice of talent as the practice of high demand, to meet the production needs of garment enterprises. However, my clothing has been in use in education and traditional teaching mode. In arranging the teaching content, emphasis on theoretical knowledge of indoctrination, but neglect to carry out practical activities. Among them, the training course content over a single, main courses constitute a major system only play the role of theory verification and deepening understanding. In fact, the structure of drawing lectures with the use of industrial plants plate there is a big gap [1].

In the curriculum, the traditional costume design and technology curriculum content, public courses and curriculum design larger proportion. Although the emphasis on style design, but seriously neglected the production process; emphasis on teaching the theory, but ignore the practical operation. Practical aspects of the proportion of small directly reduce the abilities of students. In actual operation, the prevailing emphasis on creative graduates, while ignoring the practical problems. In addition, students lack of awareness from the grassroots level, resulting in the skills of graduates and other aspects of knowledge.

In the garment industry toward the development of a diversified background in production management, technology, brand planning, marketing aspects, costume design, clothing production 
and other major changes have taken place, in the equally important position. In addition, enterprises require the same talent for clothing change and changes from the previous requirement of unity to the diversity of needs. Therefore, in the course of doing the teaching, on one hand the need to improve the focus on art theory and practical skills, but also to production management and other marketing strategies to curriculum content into the system, prompting the students to market companies have a preliminary understanding, shortened students recognize the existence of the gap, and enhance personnel training and demand coordination and unity. Construction of scientific curriculum system, you can enhance the interactive teaching and learning, Blended and coordination [2].

At this stage, most of the clothing teachers are graduated from school, and then engaged in the teaching profession. Despite some progress in terms of the knowledge structure, academic research, but since a lot of time and energy on teaching, lack of adequate social practice. Therefore, in practice experience, there are obvious shortcomings. And select the part of teachers to teach design knowledge and theoretical aspects of painting, and the lack of technical skills to explain the curriculum. Professional development of teachers in the process, there is a clear emphasis on theory ignores the skills, or artistic importance, neglect and other technical problems, limiting the development of practical ability of the students [3].

Currently, the university presence in school funding in some problems, that most of the colleges and universities campus construction and teaching training room with higher demand disjointed phenomenon is relatively backward, with only a simple mechanical device for college training room, training function is relatively simple, cannot provide students with a simulation of real production environment to the students, unable to meet the needs of enterprise development, there are a wide gap.

Part of the university will enter into a written agreement on off-campus practice bases and enterprises however, because the enterprise itself has operational characteristics and the actual production, the system cannot provide professional training for students to practice. Therefore, we cannot be in accordance with the plan, and practicum training topics will be part of the implementation of a direct impact on the progress of the students' training, and cannot achieve the desired training goal. Students in the school's practice base, it is not able to obtain the appropriate vocational skills, some off-campus practice base running just superficial [4].

\section{Reform Measures of Apparel Plate and Technology Education Teaching}

Take the school-enterprise cooperation model, strengthen the construction of campus base promotes the development of research projects, to enhance students' professional skills. Among them, the school-enterprise cooperation include the following forms of content, such as: First, in the studio, to help companies develop new products, to develop a model development process, etc.; secondly, to take school-enterprise cooperation and set up factories means to the school teachers and students can integrate into the enterprise to the true situation in production, improve students to identify problems, thinking, problem-solving skills; and finally, take horizontal issues manner, to provide technical services to work together to solve the production process exist problems, the establishment of "teaching, learning and doing" as one of the school-enterprise cooperation in personnel training mode.

Traditional training teaching process, teaching theory and practice separated from each other, emphasis on the inculcation of knowledge, but they ignore the skills training, which requires a change in the past as well as weight management light real light weight real reason misconceptions, and strengthen vocational and technical training to enhance students 'ability to adapt, enhance their 
flexibility and practicality, set knowledge transfer, quality training and skills training as a whole, to enable students while studying theoretical knowledge, while the conduct hands-on practice, enhance students' skill level.

Clothing structural design emphasizes the learning process, to enhance the ability of students to encourage students can master the ability to clothing styles to the plane perspective diagram decomposition, in which the structural design is mainly divided into two forms, namely: three-dimensional method and plane method which in turn can be divided into a group-plane method, prototyping and proportion method, so that students in-depth study of the law of decomposition principle and structure of clothing, clothing draw a plane model.

Thus, the teacher can take the task-based approach, in explaining jeans structural design process, teachers should be clear mandate classroom, prompting students can learn various modeling structure design point of jeans, then the structure drawing accurately draw jeans, then play model, fully mobilize students to participate in classroom process, enhance students identify problems [5].

Employment Education includes the following important content, such as: first, employment psychological education; second, employment guidance; third, entrepreneurship education, employment education to students to engage and guide students to establish correct ideas, enhance the sense of responsibility and sense of mission and other changes exist on student psychological past errors, eliminate misconceptions low self-esteem, anxiety, perfectionism and other students inside to enhance students' sense of competition, enhance their endurance and independence, to strengthen student employment education. Students in the course of employment, given sufficient guidance, in the course of employment guidance to enable students to master certain skills and choosing methods to enhance the students' practical ability.

In the process of quality education students, requiring students to cultivate good qualities of hard work, hard-working, etc., to enhance students' sense of cooperation to form a good team spirit, develop student excellence excellent quality and establish a personal brand Students Thought concept.

\section{Conclusion}

In summary, our clothing and craft specialty plate is still in the initial stage of development, in the process learning professional clothing, most of the designers need to learn from and imitate other art forms, the lack of adequate clothing market in the original design, only is based on existing clothing, make changes to a style of enactment and other details, cannot be regarded as a real design, rapid development in the apparel industry background, Chinese manufactured by the past into the present China creating and cultivating outstanding costume designer, it is essential to promote the development of China's garment industry

\section{REFERENCE:}

[1] Zhang Miao. Clothing plate and Technology Specialty Teaching in Higher Vocational Exploration [J]. occupation, 2013,05: 135.

[2] Yuan Fenghua,. clothing plate and professional educational reform process Discussion [J]. Jinan Vocational College, 2013,04: 49-51.

[3] Yuan Fenghua. Increase clothing plate and Technology Students Ability of clothing technology Clothing Technology Curriculum Reform [J]. Textile Industry and Technology, 2013,04: 94-95 +100 .

[4] Han Ruixia, Reflections on Higher Vocational Education Reform of clothing [J]. Education and 
Vocation, 2014,09: 170-171.

[5] Xu Xuemei. Given attention to explore the clothing plate and Technology Specialty Teaching [J]. Tianjin Textile Science, 2014,02: 57-58 + 61 . 